\title{
THE EFFECT OF WATER GAP AND PRESSURE \\ WAVE REFLECTING SURFACE ON CAVITATION EROSION OF \\ CYLINDER LINERS
}

\section{S.M. Moustafa*}

\section{ABSTRACT}

Vibratory cavitation formation and collapse and consequent material damage are controlled mainly by the driving pressure. amplitude. This amplitude is the sum of the generated pressure wave amplitude and the reflected pressure wave amplitude from : cylinder block surface.

A series of vibratory cavitation erosion tests at different -water gaps were carried out at vibration frequencies ranged from 1.85 to $6.4 \mathrm{kHz}$. Also a series of tests using a rubber disc to act as an absorbing surface instead of the normal brass bottom of test liquid container were conducted.

It was found that the erosion rate increases due to the proximity of a reflecting surface, and by suitable treatment :of the reflecting surface, this increasing can be eliminated.

\section{EXPERIMENTAL WORK}

The effect of the gap between the vibrating surface(cylinder liner) and the reflecting surface (jacket surface) on cavitation erosion of cylinder liner has been studied in the present :research by conducting a series of tests at different water gaps using a test liquid container with brass bottom. This series covered water gaps mainly from $0.5 \mathrm{~cm}$. to $10 \mathrm{~cm}$. The tests were carried out at frequencies of $1.85,3.4,4.7$ and $6.4 \mathrm{kHz}$, at vibration amplitudes of $215,72,40,23 \mathrm{\mu m}$ respectively. The cast iron alloy specimens, supplied by one :of Diesel engine makers, were tested at all four frequencies, These vibration frequencies at only the first two frequencies. $\vdots$

* Lecturer, Mech. Eng. Dept. Faculty of Eng. \& Tech. E1-Minia Univeristy

L Egypt. 
vibration frequencies for most Diesel engines.

:The effect of pressure wave reflecting surface on cavitation damage was studied by conducting a series of erosion tests using a rubber disc at the bottom of test liquid container to act as an absorbing surface instead of the normal brass bottom of the container. The tests were carried out at the same conditions as before and were conducted at,different water gaps until the effect of the gap on the erosion became negligible. At frequencies of 1.85 and $3.4 \mathrm{kHz}$ aluminium specimens were tested and at frequencies of 4.7 and $6.4 \mathrm{kHz}$ cast iron alloy specimens were tésted. A complete description of the test rig, test specimen preparation, and test procedures can be found elsewhere $[1,2]$. RESULTS AND ANALYSIS

The effect of water gap on total weight loss (T.W.L), steady state rate of weight loss (E), and maximum depth of penetrtion (M.P.D.) is shown in figures $1,2,3,4,5$ \& 6 with brass bottom test liquid container. This effect also is ahown in figures 3, 4, 5 and 6 1, with rubber bottom test liquid container. Figures $1,2,3,4,5$ and 6 show that the relationship between total weight loss, steady state rate of weight loss, or :maximum depth of penetration and water gap can all be divided into two zones. The first zone is where the deterioration changes with the change in water gap and is for gaps less than: $: 11 / \mathrm{f} \mathrm{cm}$., where $\mathrm{f}$ is the frequency in $\mathrm{kHz}$. The second $\mathrm{zone}$ is where the deterioration is approximately constant with the change in water gap and is for gaps greater than $11 / \mathrm{f} \mathrm{cm}$., a :though there is a transition zone around the change over gap of $11 / \mathrm{f} \mathrm{cm}$. In the first zone, the cast iron alloy total weight loss, steady state rate of weight loss and maximum depth of penetration are inversely proportional to the gap, to the power $1.93 / \mathrm{f}^{0.65}, 1.55 / \mathrm{f}^{0.35}$ and 0.5 respective $1 \mathrm{y}$.

With rubber reflecting surface, the effect of water gap $\vdots(t<11 / f \mathrm{~cm})$ on cavitation erosion is nearly eliminated at the four different vibration frequencies.

\section{DISCUSSION AND CONCLUSIONS}

These results illustrate the following features:

1. Test specimen eroded area, total weight loss, steady state rate of weight loss and the maximum depth of penetration at the end of the test decrease with increasing wher gap up to about $11 / \mathrm{f} \mathrm{cm.,} \mathrm{and} \mathrm{have} \mathrm{a} \mathrm{negligible} \mathrm{change} \mathrm{for} \mathrm{any}$ further increase in gap.

:2. At a water gap of less than $11 / \mathrm{f} \mathrm{cm}$, the cast iron alloy total weight loss, steady state rate of weight loss and maximum depth of penetration are inversely proportional to

$\vdots$ the gap to the power $\simeq 0.94$ (average value.), $\simeq 1.03$, (average value), and 0.5 respectively. 


\section{$r$}

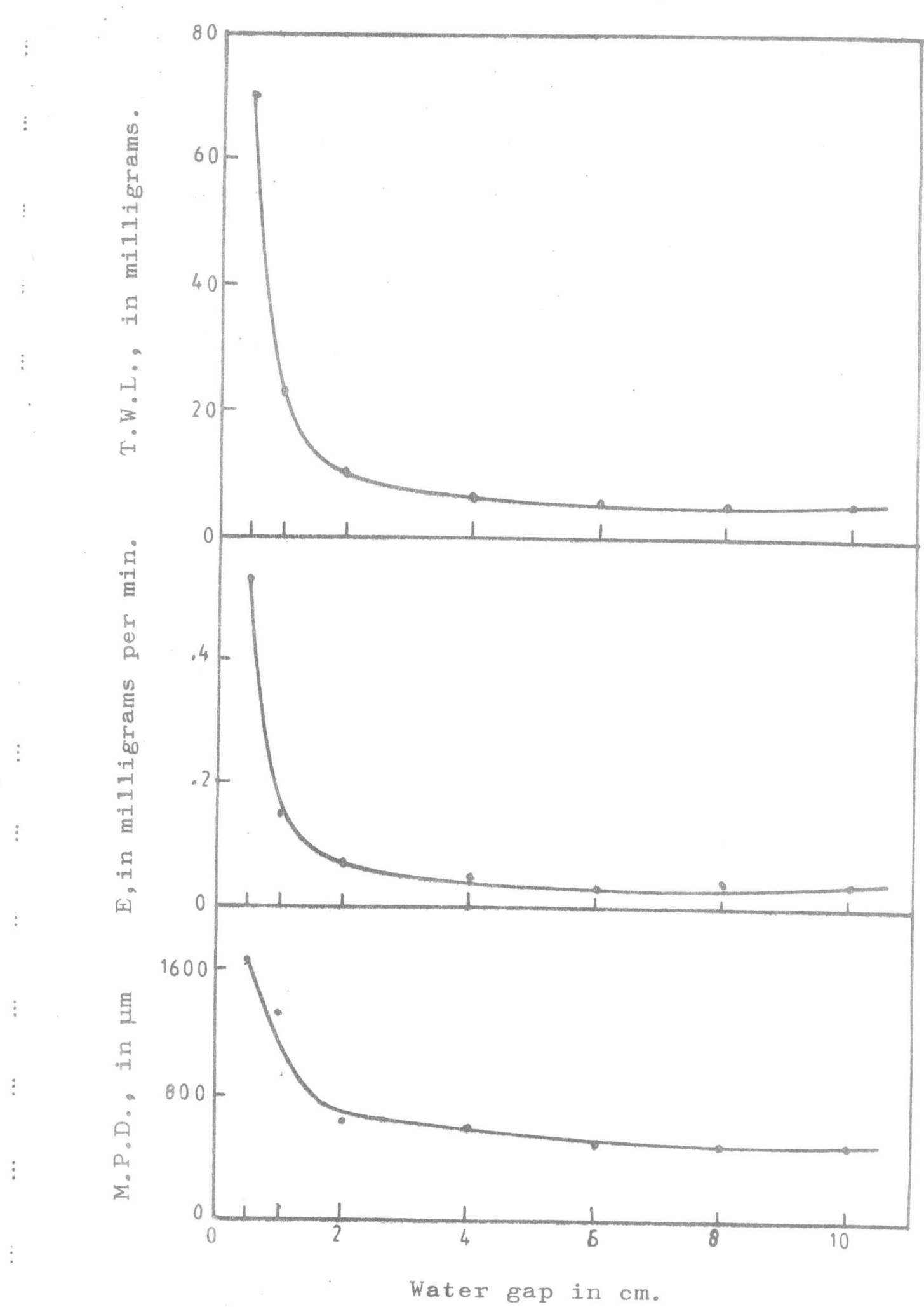

Fig. (1) The effect of water gapon erosion of cast iron alloy at frequency of $1.85 \mathrm{kHz}$

L. 
$r$

स

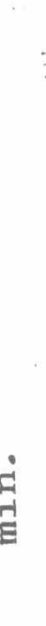

30

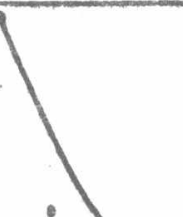

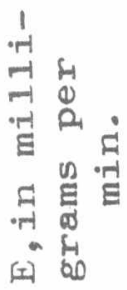

$$
0
$$

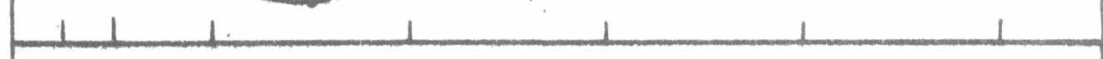

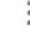

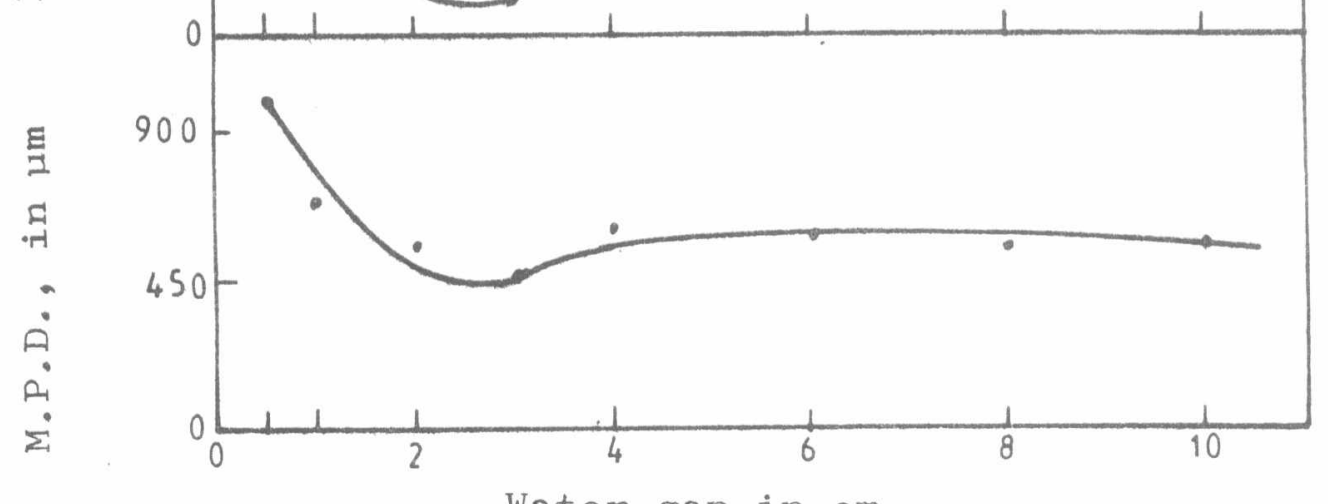

Water gap in $\mathrm{cm}$.

Fig. (2) The effect of water gap on erosion of cast iron alloy at frequency of $3.4 \mathrm{kHz}$.

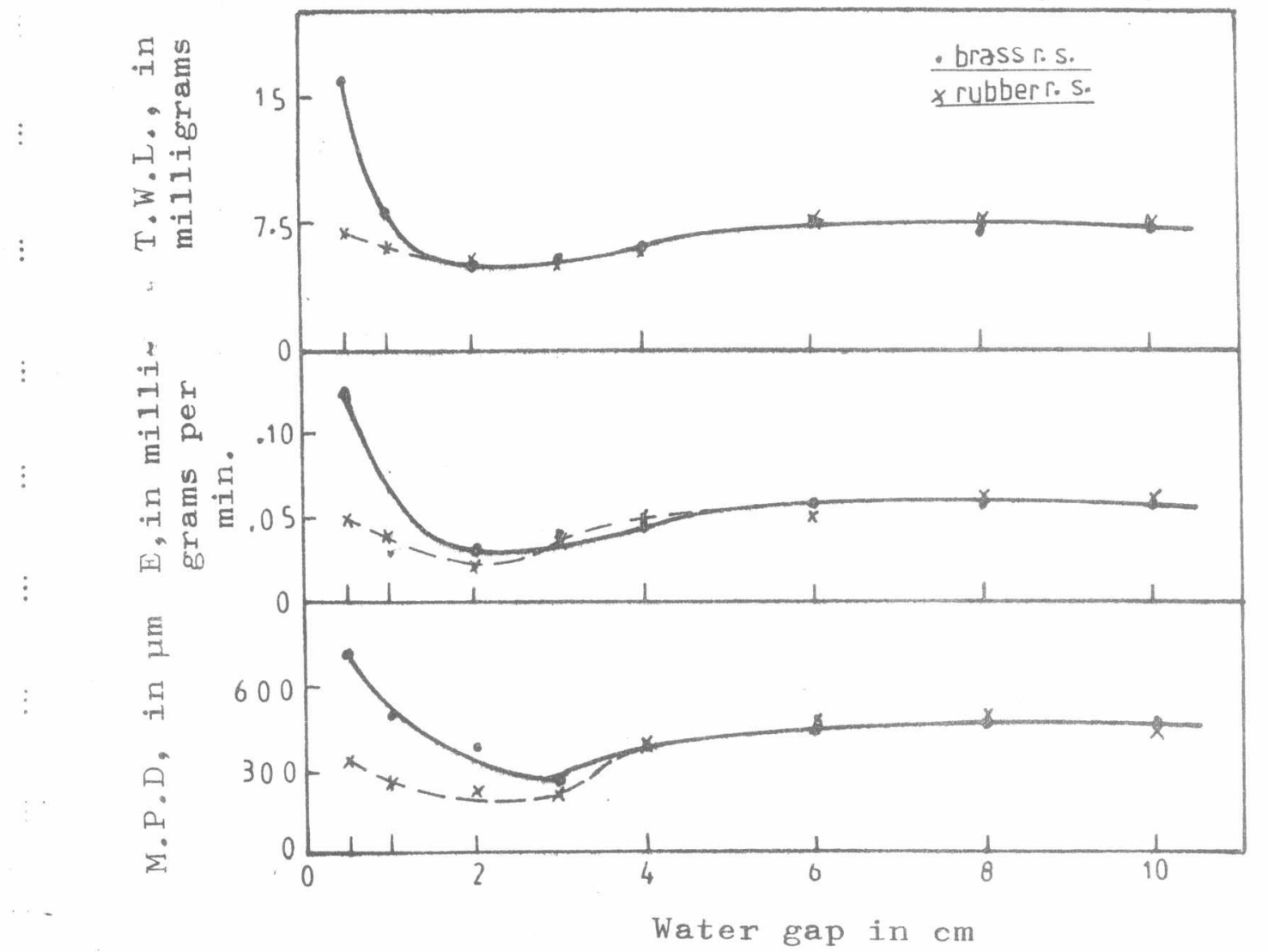

Fig. (.3) The effect of 'water..gap on erosion of cast iron alloy at frequency of $4.7 \mathrm{kHz}$. 

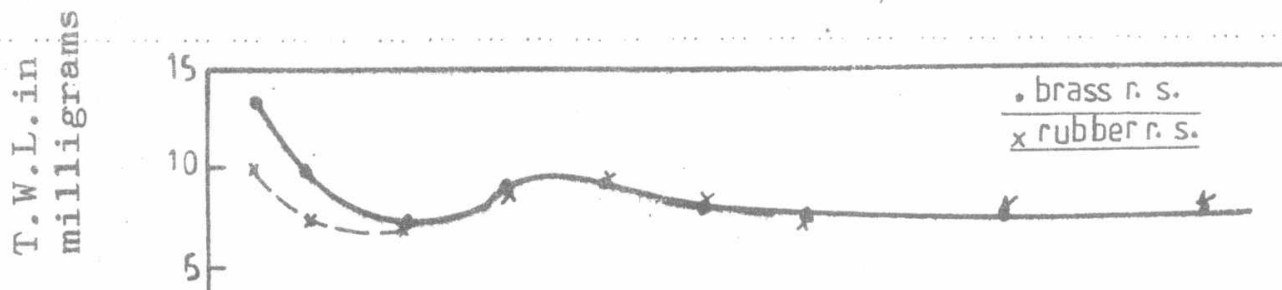

告

되

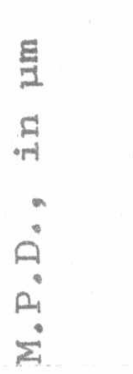

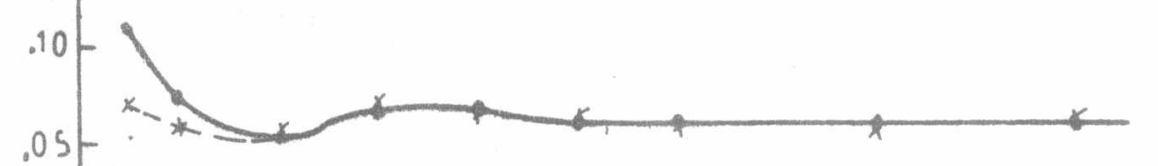

我

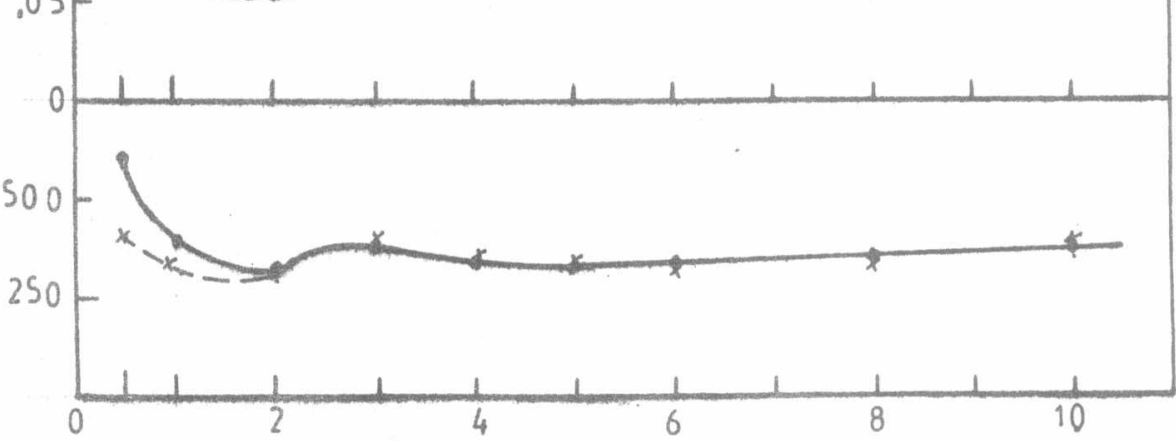

Water gap in $\mathrm{cm}$

Fig. (4) The effect of water gap on erosion of cast iron alloy at frequency of $6.4 \mathrm{kHz}$.

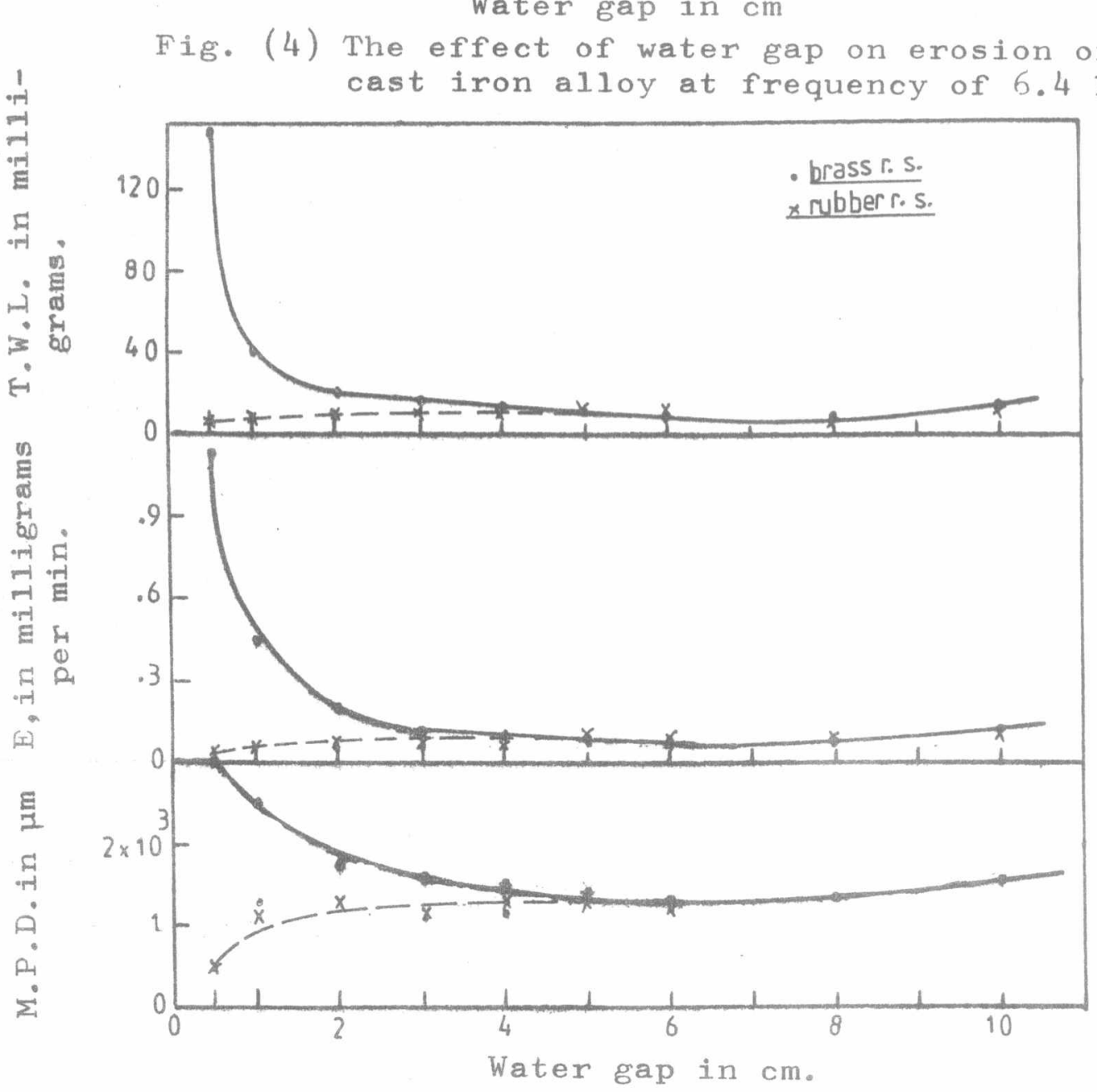

i. ...

Fig $\frac{1}{9}$

(5)

The effect of erosion of aluminium at frequency of $1: 85 \mathrm{kHz}$. 
\begin{tabular}{|l|l|}
\hline DYN-17 & 186 \\
\hline
\end{tabular}

FIRST A.M.E. CONFERENCE

29-31 May 1984, Cairo

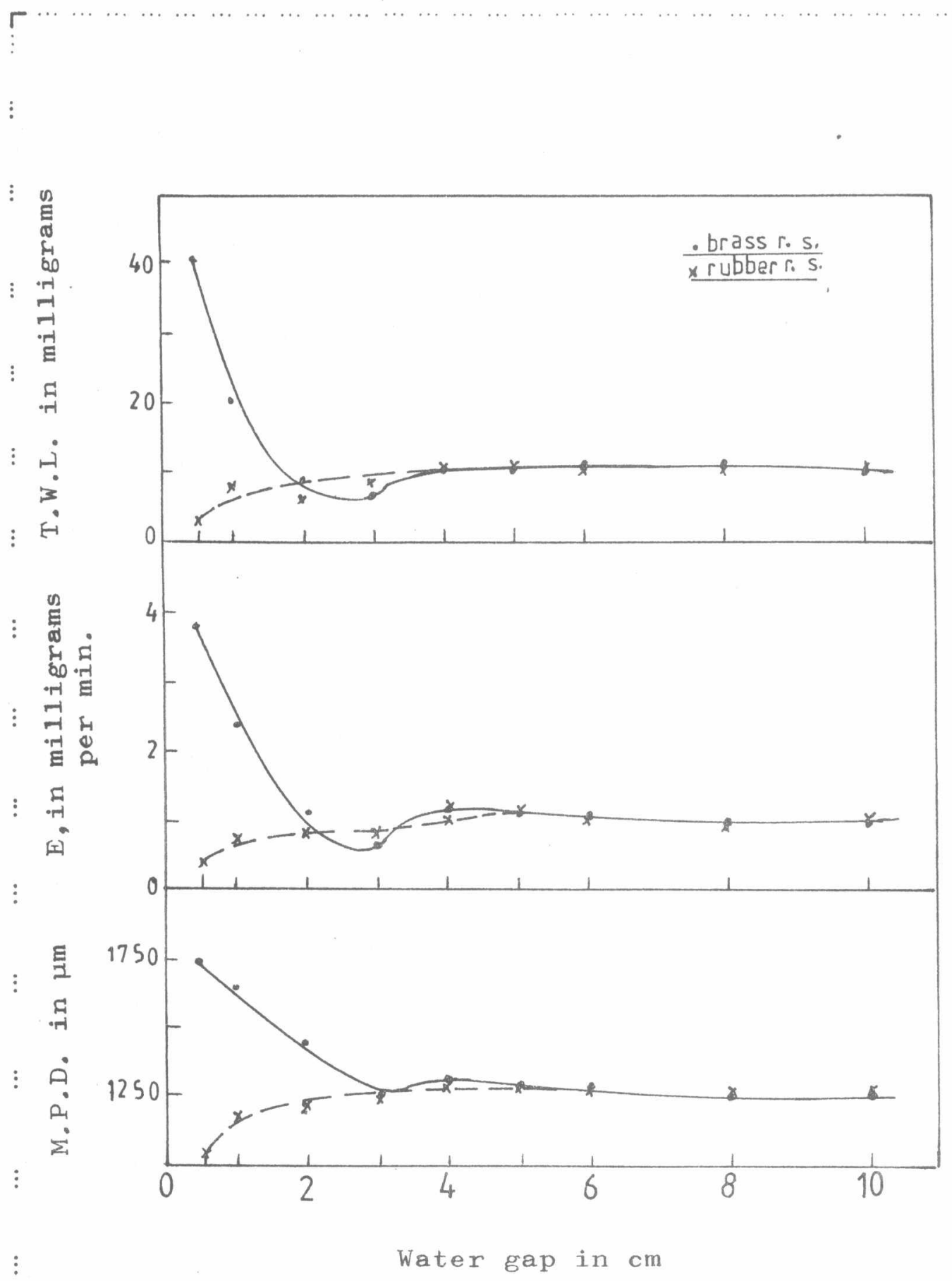

Fig. (6) The effect of water gap on erosion of aluminium at frequency of $3.4 \mathrm{kHz}$. 
\begin{tabular}{|l|l|}
\hline DYN-17 & 187 \\
\hline
\end{tabular}

FIRSI A.M.E. CONFERENCE

29-31 May 1984, Cairo

3. With the rubber disc at the bottm of test liquid container, changing water gap. there is slight decrease in specine the gap below $1.0 \mathrm{~cm}$, frequencies of 1.85 and $3.4 \mathrm{kHz}$, no deterioration with

of $4.7 \mathrm{kHz}$ and a slight $3.4 \mathrm{kHz}$, no change at a frequency

4. The effect of the water increase at a frequency of $6.4 \mathrm{kHz}$. similar to that of cast iron alloy.

It is generally understood that cavitation formation and collapse and consequent material damage are controlled mainly when the other test conditions at the test specimen face of the driving pressure is the remain constant. The amplitude: wave amplitude and the the test liquid container base. pressure wave amplitude from amplitude depends on the generated The reflected pressure wave gap, the reflecting coefficent of the fluid and the driving of the base, the damping factors certain value of water gap thequency. Therefore above a pressure wave at the test specimentitude of the reflected that a further increase in gap pressure amplitude.

The present rosults, are in general agreement with Robinson[3] small gaps (0.3 wave lengths) which the finding reported here, wamely that damage ly conflicts with imall gaps. The decrease, namely that damage increase at could be because the gap at damage observed by Thiruvengadam corresponds to the beginning of wave length in his work im. (the wave length is not stated). The present results also by rapid increase as the wet gap which was however followed This discrepancy could also water gap was decreased further. frequencies (e.g. $15 \mathrm{kHz}$ ) are different the conditions at high range of the present tests. :

The effect of water gap on total weight loss and steady state rate of weight loss, depends on the driving frequency, such This suggest that the rate with increasing driving frequency. linear and reaches a limiting material deterioration is non properties. The effect of water gap on maximum its mechanical. penetration is frequency independent on maximum depth of sensitive to the change in gap thent because it is less

With the rubber disc at the bottom of the the effect of decreasing the gap belowe test liquid container erosion has been reduced with all low $11 / \mathrm{f} \mathrm{cm}$. on cavitation damping the incident pressure wave. This frequencies due to amplitude of the reflected pressure wave, damping reduces the diriving pressure at the test specimen face the amplitude of the cavitation thrust forces. i. 
As a result of these investigations, the reduction of cavitation attack on cylinder liners can be made by increasing the minimum water gap between the liner and the water jacket : (or adjacent liner). If the increase in the gap is limited by other design considerations, the adverse effect of pressure. reflection can be reduced by suitable absorbing surface treatment.

:

\section{REFERENCES}

1. Moustafa, S.M. "Cavitation erosion of cylinder liners" $\mathrm{Ph} . \mathrm{D}$. thesis, Southampton university, England, 1981.

2. Moustafa, S.M., "The effect of vibra tion on cavitation erosion of cylinder liners". Proceedings of the second fluid mechanics and hydraulic conference, E1-Mansoura, Egypt, 1983, pp. 269-295.

3. Robinson, L.E., Holmes, B.A. and Lieth, W.G., "Progress report on standardization of the vibratory-cavitation

! test". Trans, ASME, 80, 1957, pp. 103-107.

4. Thiruvengadam, A. and Preiser, H.S. "On testing materials

: for cavitation damage resistance". Jr. Ship research, 1964, pp. 39-57. 